\title{
Insulin Administration Protects from Paraplegia in the Rat Aortic Occlusion Model ${ }^{1}$
}

\author{
Daniel R. LeMay, B.S., Alice C. Lu, Gerald B. Zelenock, M.D. AND \\ Louis G. D'Alecy, D.M.D., Ph.D. \\ Department of Physiology and Surgery, University of Michigan Medical School, Ann Arbor, MI 48109
}

Presented at the Annual Meeting of the Association for Academic Surgery, Orlando, FL, November 1-4, 1987

\begin{abstract}
The effect of insulin induced hypoglycemia was evaluated in a rat aortic occlusion model of ischemic paraplegia. One hour before aortic occlusion, $200-250 \mathrm{~g}$ Sprague-Dawley rats received either $1 \mathrm{cc}$ of saline or 0.5 units regular insulin in 1 ce saline. Rats were then anesthetized, intubated, and ventilated with halothane $(1-1.5 \%)$. The aortic arch was exposed and snares were placed on the right and left subclavian arteries and the aorta distal to the left subclavian. The three vessels were occluded for 10 min. Lower extremity neurologic deficit was evaluated at $1,4,18$, and $24 \mathrm{hr}$ postocclusion based on a 15 -point scale $(0=$ normal, $15=$ severe deficit $)$. Lower extremity neurologic deficit was significantly decreased in the insulin-treated group at 18 and $24 \mathrm{hr}$ postocclusion $(P=0.005$ and 0.006 , respectively, Student's $t$ test). Blood glucose concentration was significantly lower at the time of occlusion in the insulin-treated group when compared to the saline-treated group $(P=0.001)$. We conclude that in this rat model of paraplegia, insulin induced hypoglycemia is associated with a reduction in lower extremity neurologic deficit produced by temporary aortic occlusion. (c) 1988 Academic Press, Inc.
\end{abstract}

\section{INTRODUCTION}

Our laboratory has recently demonstrated that exogenous administration of glucose greatly exacerbates neurologic damage following spinal cord ischemia induced by aortic clamping in both the rabbit [15] and the rat [11]. The adverse effect of hyperglycemia has also been documented in several other models involving CNS ischemia $[5,6,16,18$, $19,23]$. The prospect that euglycemia or mild hypoglycemia, whether spontaneous or insulin induced, might be protective in spinal cord ischemia has received less attention. Theoretically, in anticipation of an intraoperative spinal cord ischemic stress, insulin could be utilized to maintain blood glucose in normal to low normal ranges, and thereby afford protection against the risk of hyperglycemia exacerbated neurologic damage. Of potential concern are the conflicting results of some studies on the direct effects of insu-

\footnotetext{
${ }^{1}$ Supported in part by grants from the Veterans Administration and the Committee on Student Medical Research of the University of Michigan Medical School.
}

lin on brain glucose utilization. While some authors demonstrate either an absence [10] or a suppressing effect [7] of insulin on brain glucose utilization which could be beneficial, others have shown insulin stimulates glucose uptake $[3,8]$ and utilization $[4,14]$ in neural tissues which would be potentially damaging. The goal of this study was to examine the effects of insulin pretreatment on spinal cord ischemic injury and paraplegia produced following aortic occlusion in the rat. This study had three discrete objectives: (1) to define the time course of blood glucose changes in normal rats following ip injection of 0.5 units of insulin, (2) to document blood glucose concentrations in saline- and insulin-treated rats undergoing aortic occlusion at preoperative and preocclusion time points, and (3) to monitor postischemic neurological deficit to determine if preoperative insulin significantly alters neurologic outcome.

\section{MATERIALS AND METHODS}

Male Sprague-Dawley rats, 2-3 months of age, weighing $200-250 \mathrm{~g}$ were individually 
housed in metal cages with free access to food and water. Animal care complied with the Principles of Laboratory Animal Care and the Guide for the Care and Use of Laboratory Animals (NIH Publication No. 85-23, 1985). One hour before occlusion of the vessels, rats received intraperitoneal injections of either $1 \mathrm{cc}$ of normal saline or 0.5 units of regular insulin in $1 \mathrm{cc}$ of normal saline. Whole blood $(0.3 \mathrm{cc})$ was immediately taken from a tail snip for a control blood glucose level. Forty-five min later rats were weighed and then anesthetized by placing them in a chamber containing $2 \%$ halothane. Tracheal intubation with a $2.5-\mathrm{mm}$ o.d. tube $8 \mathrm{~cm}$ long was assisted by a neonatal laryngoscope reduced to a blade width of $7 \mathrm{~mm}$. The rat was then ventilated with an open circuit volume ventilator (Phipps and Bird) at 90-100 cycles per min with $1.0-1.5 \%$ halothane. Temperature was continuously monitored with a probe inserted $3.5 \mathrm{~cm}$ into the rectum and maintained between 35 and $36^{\circ} \mathrm{C}$ with a thermal pad.

A longitudinal incision was made through the skin in the sternal region. The chest wall was incised from the apex of the manubrium caudad along the left sternal border, through the second rib, to the third rib carefully avoiding the left internal thoracic artery. The thymus was excised and the aortic arch was isolated distal to the left subclavian artery. A $15-\mathrm{cm}$ segment of catheter (PE 10) was placed around the aorta, avoiding the left vagus nerve and recurrent laryngeal nerve, and the free ends were passed through a 4-cm segment of tubing (PE 160) creating a snare. The origins of the right and left subclavian arteries were isolated and snares were placed in a similar manner (Fig. 1). Body temperature was recorded and a $0.3 \mathrm{cc}$ blood sample was taken from a tail snip for a preocclusion glucose level. The three snares were pulled and secured with a clip thus occluding each vessel. Occlusion of each vessel was verified by inspection of the snare site and the vessel distal to the snare. Ten centimcters of water positive end expiratory pressure (PEEP) was started and maintained through the 10 -min occlusion period. The snares exited the incision cephalad to the manubrium and the chest was closed in three layers up to the snares with 4-O silk.

At the end of the occlusion period, the snares were released and withdrawn and the closure was completed. The anesthesia and PEEP were discontinued and extubation was performed when the rat demonstrated whisker activity and maintained voluntary ventilation when disconnected from the ventilator. A neurologic deficit score was assigned at $1,4,18$, and $24 \mathrm{hr}$ postocclusion to quantify hindlimb neurologic deficit (Table 1).

Blood glucose analysis was done on a reflectance spectrometer (Ames seralyzer). Additional studies on blood glucose changes over time in saline control and insulintreated groups were done on rats not undergoing surgery.

Data analysis was performed using the Michigan Interactive Data Analysis System (MIDAS) on an IBM 3090-400 computer. Neurologic deficit scores were compared between insulin-treated and saline-treated groups of rats using the Student's $t$ test and $P$ values are given. All average values are expressed as means \pm 1 SEM with $n$ denoting sample size.

\section{RESULTS}

\section{Neurologic Deficit}

Neurologic deficit was scored at 1, 4, 18, and $24 \mathrm{hr}$ postocclusion. At 1 and $4 \mathrm{hr}$ postocclusion there was no significant difference detected between saline-treated and insulintreated rats (Fig. 2). Thereafter, insulintreated rats showed progressive improvement in neurologic function, whereas saline rats remained significantly impaired such that at 18 and $24 \mathrm{hr}$ postocclusion the saline-treated rats had a significantly greater neurologic deficit $(P=0.005$ at 18 $\mathrm{hr}$ and $P=0.006$ at $24 \mathrm{hr}$ postocclusion, respectively). 


\section{Blood Glucose Changes}

Nonoperated rats. Five rats receiving $1 \mathrm{cc}$ of saline and four receiving 0.5 units regular insulin in $1 \mathrm{cc}$ saline intraperitoneally had blood glucose concentrations monitored over a 5 -hr period. Nonoperated salinetreated rats demonstrated little change in blood glucose over the 5-hr period (Fig. 3). Nonoperated insulin-treated rats had similar baseline blood glucose levels when compared to the saline-treated group but following the insulin injection blood glucose showed a progressive decline to a mean of $44 \mathrm{mg} / \mathrm{dl}$ at $1 \mathrm{hr}$ postinjection and then began to rise with two of the four rats undergoing hyperglycemic rebound.

Operative rats. Figure 4 demonstrates that saline controls had a preoperative mean blood glucose of $153 \mathrm{mg} / \mathrm{dl}$, and with anesthetic and operative stress this significantly increased to a preocclusion level of 218 $\mathrm{mg} / \mathrm{dl}(P=0.002)$. Insulin-treated rats had a preoperative mean blood glucose of 147 $\mathrm{mg} / \mathrm{dl}$ which was similar to that of the saline-treated control group $(P=0.55)$, and despite similar operative stress this signifcantly decreased to a preocclusion mean level of $89 \mathrm{mg} / \mathrm{dl}(P=0.002)$. Preocclusion mean blood glucose was significantly lower in insulin-treated rats than in saline-treated rats $(P=0.0001)$.

\section{DISCUSSION}

Our laboratory and several others using different animal models of CNS ischemia have documented that elevated blood glucose exacerbates ischemic neurologic deficits and impairs outcome $[5,6,11,15,16,18,19$, 23]. Several clinical studies done by a variety of investigators $[2,13,20,22]$ have shown that a CNS ischemic event occurring in the presence of hyperglycemia has a significantly

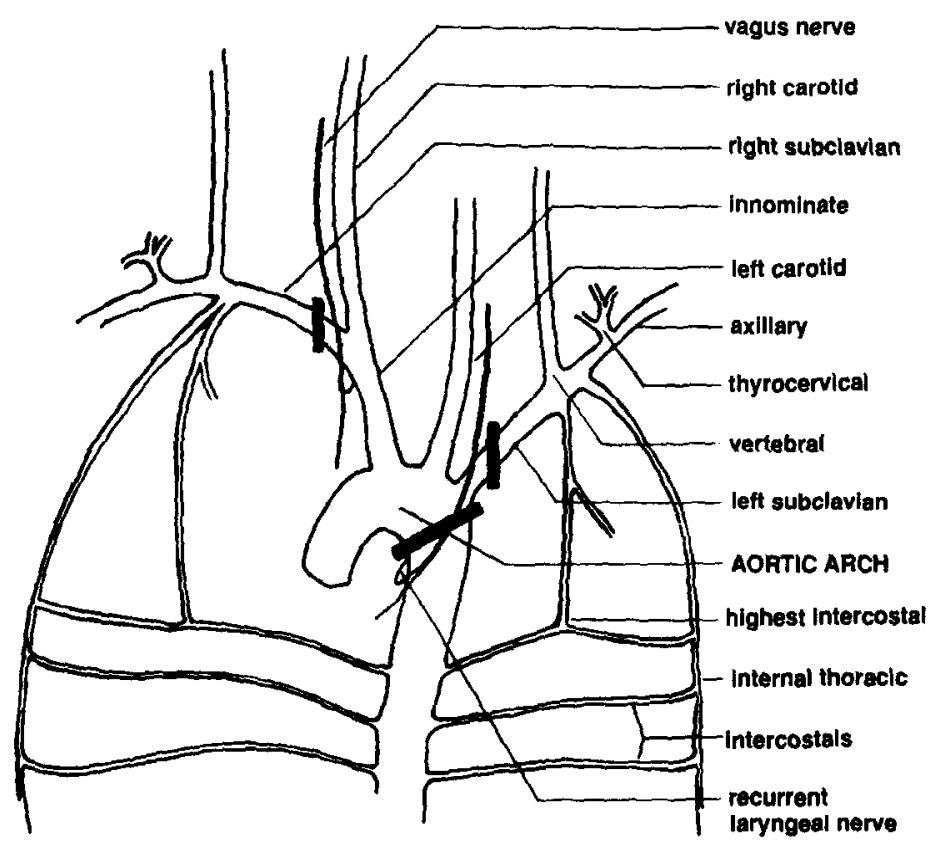

Fig. 1. Anatomic representation of the major blood vessels of the thorax. The aortic branches are the major blood supply to the spinal cord. Snares (black bars) are placed to minimize aortic blood supply to the spinal cord and collateral flow to the aorta from subclavian artery branches. The left vagus and recurrent laryngeal nerves remain outside of the aortic snare. Blood supply to the spinal cord remains open along the route through the carotid artery to the Circle of Willis and retrograde through the basilar artery into the anterior spinal artery. 
TABLE 1

SPINAL CORd IsChemia Neurologic Deficit SCORE

Deficit

Score

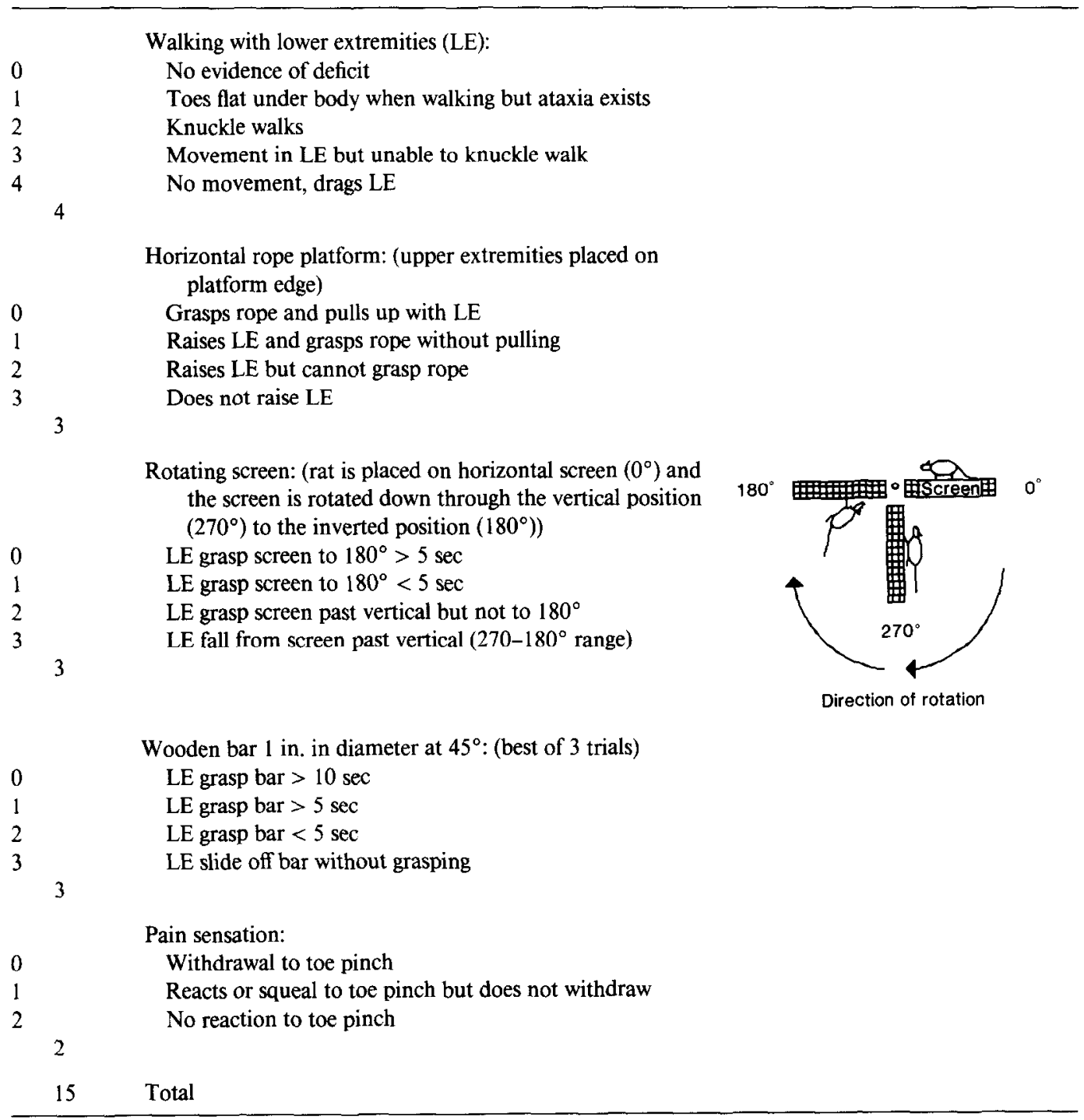

Note. Numerical score assigned to a degree of neurologic deficit. A score of zero (0) indicates no deficit detected, with increasing numbers corresponding to increasing deficit.

worse outcome than nonhyperglycemic ischemia. In a study by Pulsinelli [20] nondiabetic stroke patients faired better than diabetic stroke patients. In the same study when nondiabetic stroke patients had blood glu- cose above $120 \mathrm{mg} / \mathrm{dl}$ only $43 \%$ returned to work, while those with blood glucose below $120 \mathrm{mg} / \mathrm{dl}, 76 \%$ returned to work.

In the clinical setting hyperglycemia is commonplace. Diabetes as well as psycho- 


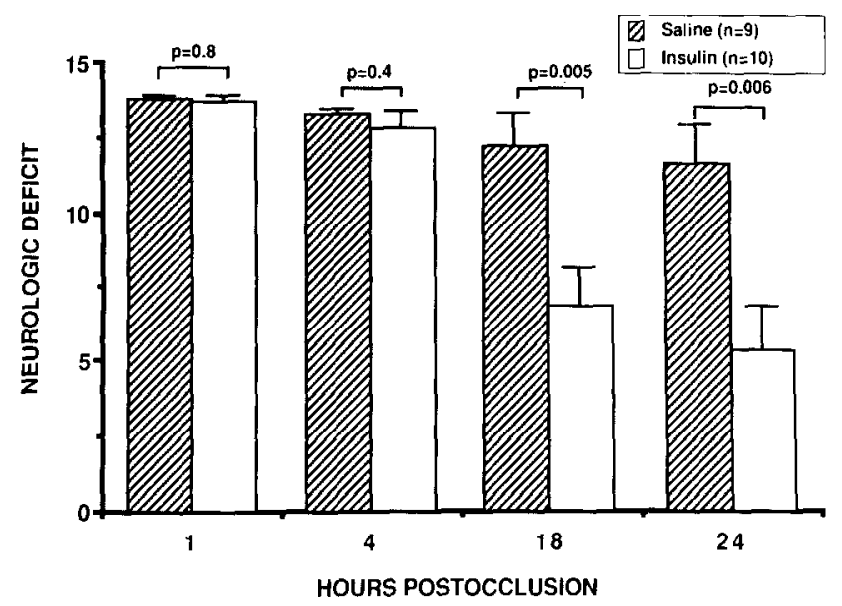

FIG. 2. Total deficit score at $1,4,18$, and $24 \mathrm{hr}$ postocclusion for the saline-treated group and the $0.5 \mathrm{U}$ insulin-treated group. The insulin-treated group showed significant reduction in neurologic deficit over the saline-treated group at 18 and $24 \mathrm{hr}$ postocclusion. Statistical comparison was performed by Student's $t$ test with $P$ values indicated above the respective bars.

logical and operative stress tend to elevate blood glucose. Control of blood glucose concentrations is usually approached in terms of long-term chronic control and acute varia-

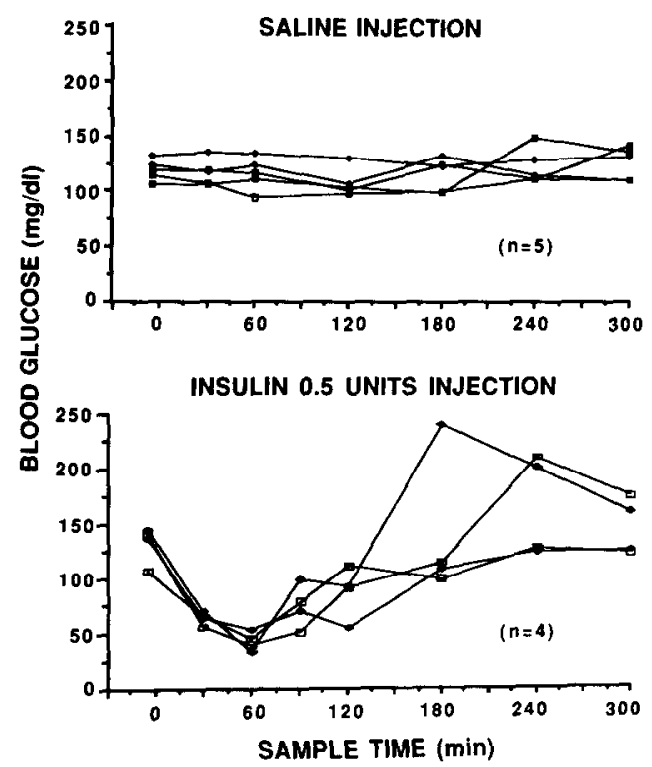

FIG. 3. Blood glucose changes in nonoperated rats following saline (top) or $0.5 \mathrm{U}$ insulin (bottom) injections. Saline-treated rats showed no significant change in blood glucose concentration while insulin-treated rats reached an average minimum of $44 \mathrm{mg} / \mathrm{dl}$ at $1 \mathrm{hr}$ with two of four rats undergoing hyperglycemic rebound. tions between 100 and $300 \mathrm{mg} / \mathrm{dl}$ are not generally considered reasons for concern. Blood glucose concentrations in the 200 to $300 \mathrm{mg} / \mathrm{dl}$ range are not uncommon in operative patients or in patients experiencing stroke or trauma, and in the operative setting control of blood glucose concentration has historically not been of great concern unless

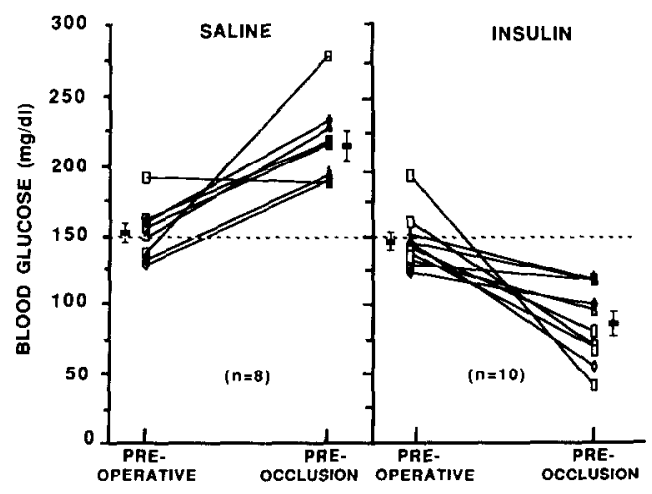

FIG. 4. Blood glucose changes in operative rats. Saline-treated rats showed a significant increase while 0.5 $\mathrm{U}$ insulin-treated rats showed a significant decrease in mean blood glucose concentration $(P=0.002$ in both cases, paired Student's $t$ test). Preocclusion mean blood glucose was significantly lower in insulin-treated rats than in saline-treated rats $(P=0.0001$, unpaired Student's $t$ test). 
grossly abnormal concentrations are reached (i.e., greater than $300 \mathrm{mg} / \mathrm{dl}$ ). However, inferences drawn from normoxic, nonischemic patients should not be generalized to other clinical settings involving regional or global ischemic stress. Settings where such variations would almost certainly be damaging would include cardiac arrest, evolving stroke patients, and patients undergoing surgical procedures associated with temporary CNS ischemia.

Of the factors which may play a role in ischemic-hypoxic neurologic injury, elevated tissue lactate resulting from glucose metabolism has been implicated as the major metabolic event that is associated with glucose exacerbation of ischemic neurologic injury. [17, 21, 24] A possible means of reducing the amount of glucose available for conversion to lactate during ischemia would be to utilize insulin. Traditionally the CNS had been considered to be independent of insulin effects on glucose uptake and metabolism but this view has been challenged. [1] Insulin has been reported to either have no effect [10] or a suppressing effect [7] on brain glucose utilization, which could explain its protective effects in our model. Others have found that insulin stimulates glucose uptake $[3,8]$ and utilization $[4,14]$ in neural tissue including whole rat brain or cultured rat glial cells. If this were the case, then under ischemic conditions one might anticipate an adverse effect of insulin due to local CNS tissue lactate accumulation in response to increased glucose uptake. At the present time the direct effect of insulin on nervous tissue remains controversial. There are regional differences in the brain's response to insulin. Further, the effect of insulin on glucose utilization by the spinal cord has not been specifically examined.

There are several mechanisms by which insulin could be protective in spinal cord ischemia. Insulin decreases hepatic glycogenolysis and gluconeogenesis, lowers blood glucose by preferentially increasing uptake into muscle and fat, and may reduce the glucose available for spinal cord metabolism.
We cannot exclude the possibility that insulin could suppress the utilization of glucose by the spinal cord. Alternatively, insulin may have an effect on the spinal cord that is protective during ischemia which does not involve alterations in glucose supply or utilization. This study does not specifically identify any one or a combination of the above effects as the mechanism of protection.

Multiple interventions have been utilized to reduce the severity of deficit following ischemic-hypoxic neurologic injury. [9] However, rigorous maintenance of normoglycemia or mild hypoglycemia utilizing insulin as a primary intervention in a spinal cord ischemic model has not been evaluated for its protective effect. Theoretically, the reduced availability of glucose as an energy substrate would reduce the formation and accumulation of lactate that normally occurs under ischemic conditions. In a complimentary study, our laboratory has demonstrated a protective effect of insulin-induced mild hypoglycemia in a rat model of cerebral ischcmia. [12] The protection demonstrated in the cerebral ischemia model was dependent on the severity of hypoglycemia, and a lower critical level of approximately $65 \mathrm{mg} / \mathrm{dl}$ was determined as the level below which protection was reversed. Although not specifically tested in this study we would anticipate that severe hypoglycemia would also be detrimental in the setting of spinal cord ischemia.

In this rat model of ischemic paraplegia, insulin-induced mild hypoglycemia affords a substantial degree of protection. Therefore, carefully monitored insulin administration offers a potential therapeutic approach to reducing ischemic spinal cord injury by inducing mild hypoglycemia-euglycemia or by preventing hyperglycemia.

\section{ACKNOWLEDGMENT}

We thank Carol Goodenough for her assistance with illustration.

\section{REFERENCES}

1. Baskin, D. G., Figlewicz, D. P., Woods, S. C., Porte, Jr., D., and Dorsa, D. M. Insulin in the Brain. Ann. Rev. Physiol. 49: 335, 1987. 
2. Candelise, L., Landi, G., Orazio, E. N., and Boccardi, E. Prognostic significance of hyperglycemia in acute stroke. Arch. Neurol. 42: 661, 1985.

3. Clarke, D. W., Boyd, F. T., Kappy, M. S., and Raizada, M. K. Insulin binds to specific receptors and stimulates 2-deoxy-D-glucose uptake in cultured glial cells from rat brain. J. Biol. Chem. 259: 11,672, 1984.

4. Clarke, D. W., Boyd, F. T., Kappy, M. S., and Raizada, M. K. Insulin stimulates macromolecular synthesis in cultured glial cells from rat brain. $A m . J$. Physiol. 249: C484, 1985.

5. D'Alecy, L. G., Lundy, E. F., Barton, K. J., and Zelenock, G. B. Dextrose containing intravenous fluid impairs outcome and increases death after eight minutes of cardiac arrest and resuscitation in dogs. Surgery 100: 505, 1986.

6. Ginsberg, M. D., Welsh, Г. A., Rider, W., and Budd, W. W. Deleterious effect of glucose pretreatment on recovery from diffuse cerebral ischemia in the cat. Parts I and II. Siroke 11: 347, 1980.

7. Grunstein, H. S., James, D. E., Storlien, L. H., Smythe, G. A., and Kraegen, E. W. Hyperinsulinemia suppresses glucose utilization in specific brain regions: In vivo studies using the euglycemic clamp in the rat. Endocrinology 116: 604, 1985.

8. Hertz, M. M., Paulson, O. B., Barry, D. I., Christiansen, J. S., and Svendsen, P. A. Insulin increases glucose transfer across the blood-brain barrier in man. J. Clin. Invest. 67: 597, 1981.

9. Hoff, J. T. Cerebral protection. J. Neurosurg. 65: $579,1986$.

10. Hom, F. G., Goodner, C. J., and Berrie, M. A. A $\left[{ }^{3} \mathrm{H}\right] 2$-deoxyglucose method for comparing rates of glucose metabolism and insulin responses among rat tissues in vivo. Diabetes 33: 141, 1984.

11. LeMay, D. R., Neal, S., Neal, S., Zelenock, G. B., and D'Alecy, L. G. Paraplegia in the rat induced by aortic cross clamping: Model characterization and glucose exacerbation of neurological deficit. J. Vasc. Surg. 6: 383, 1987.

12. LeMay, D. R., Gehua, L., Zelenock, G. B., and D'Alecy, L. G. Insulin administration protects neurologic function in the rat cerebral ischemia model. Stroke, in press.

13. Longstreth, W. T., Inui, T. S., Cobb, L. A., and Copass, M. K. Neurologic recovery after out-of-hospital cardiac arrest. Ann. Intern. Med. 98: 588, 1983.
14. Lucignani, G., Namba, H., Nehlig, A., Porrino, L. J., Kennedy, C., and Sokoloff, L. Effects of insulin on local cerebral glucose utilization in the rat. $I$. Cereb. Blood Flow Metabol. 7: 309, 1987.

15. Lundy, E. F., Ball, T. D., Mandell, M. A., Zelenock, G. B., and D'Alecy, L. G. Dextrose administration increases sensory/motor impairment and parapalegia following infrarenal aortic occlusion in the rabbit. Arch. Surg. 102: 737, 1987.

16. Myers, R. E., and Yamaguchi, S. Nervous system effects of cardiac arrest in monkeys: Preservation of vision. Arch. Neurol. 34: 65, 1977.

17. Nilsson, L., and Siesjo, B. K. The effect of deep halothane hypotension upon labile phosphates and upon extra- and intracellular lactate and pyruvate concentrations in the rat brain. Acta Physiol. Scand. 81: 508, 1971.

18. Plum, $\mathrm{F}$. What causes infarction in ischemic brain? The Robert Wartenberg Lecture. Neurology 33: 222, 1983.

19. Pulsinelli, W. A., Waldman, S., Rawlinson, D., and Plum, F. Moderate hyperglycemia augments ischemic brain damage: A neuropathologic study in the rat. Neurology 32: 1239, 1982.

20. Pulsinelli, W. A., Levy, D. E., Sigsbee, B., Scherer, $P$. , and Plum, F. Increased damage after ischemic stroke in patients with hyperglycemia with or without established diabetes mellitus. Amer. J. Med. 74: 540, 1983.

21. Rehncrona, S., Rosen, I., Siesjo, B. K., Kalimo, H., Soderfeldt, B., and Olsson, Y. Brain lactic acidosis and ischemic cell damage. Parts I and II. J. Cereb. Blood Flow Metabol. 1: 297, 1981.

22. Riddlc, M. C., and Hart, J. Hyperglycemia, recognized and unrecognized, as a risk factor for stroke and transient ischemic attacks. Stroke 13: 356, 1981.

23. Siemkowicz, E., and Hansan, A. J. Clinical restitution following cerebral ischemia in hypo-, normo-, and hyperglycemic rats. Acta Neurol. Scand. 58: 1, 1978.

24. Yoshida, Y., Busto, R., Martinez, E., Scheinberg, P., and Ginsberg, M. D. Regional brain energy metabolism after complete versus incomplete ischemia in the rat in the absence of severe lactic acidosis. $I$. Cereb. Blood Flow Metab. 5: 490, 1985. 